\title{
Conflito Étnico, Direitos Humanos e Intervenção Internacional
}

\author{
Tullo Vigevani \\ Thiago Lima \\ Marcelo Fernandes de Oliveira
}

\section{INTRODUÇÃO}

ste artigo tem por objetivo discutir como os conflitos étnicos afe-

¿ tam negativamente os direitos humanos. Compreender as razões pelas quais os Estados e as sociedades buscam agir em relação a esses mesmos conflitos é outro propósito de nossa reflexão. Veremos ainda que os impulsos em direção à intervenção internacional não estão dissociados dos interesses particulares e imediatos.

Segundo algumas interpretações, a Conferência das Nações Unidas realizada em Viena em 1993 pareceu universalizar os direitos humanos, apresentando seus resultados não apenas como reflexo da perspectiva ocidental, embora esta tenha sido predominante. Para alguns, vai se ampliando a percepção de que, na contemporaneidade, o Estado deixou de ser o ente coletivo detentor absoluto da soberania nacional, no âmbito do qual se exerce de forma irrestrita o monopólio legítimo da violência, ou, em uma definição jurídica, ele deixou de constituir-se como um conjunto formado por território, povo e soberania, no qual nenhum ator externo tem o direito de interferir. Segundo essa doutrina, o Estado passa a ter como uma de suas funções mais importantes perante a comunidade internacional a garantia não apenas das condições básicas para a vida humana, mas também para a expansão dos direitos que lhe são inerentes.

DADOS - Revista de Ciências Sociais, Rio de Janeiro, Vol. 51, n-1, 2008, pp. 183 a 213. 
No que se refere aos conflitos étnicos, o avanço do debate sobre os direitos humanos, o surgimento de atores não-estatais transnacionais e a emergência do tema como issue relevante das relações internacionais colocam em evidência acontecimentos domésticos de Estados. Conforme pode ser constatado pelos acontecimentos ocorridos na última década do século XX e no início do século XXI (Iugoslávia, Afeganistão, Iraque, Ruanda, Sudão, Israel-Palestina, entre outros), esses episódios foram utilizados de forma seletiva para justificar intervenções internacionais apresentadas como de caráter humanitário, ainda que tal caráter nem sempre tenha sido suficiente para explicá-las.

Neste artigo, pretendemos discutir uma modalidade de conflito aquele determinado por questões étnicas - que questiona a capacidade do Estado de garantir e expandir os direitos humanos, o que, de acordo com algumas interpretações, abriria espaço para a intervenção internacional. Tendo em vista tratar-se aqui de uma discussão conceitual, sem ancoragem direta em exemplos empíricos, não será nosso objetivo defender ou condenar a intervenção internacional, mas sim buscar contribuir para uma melhor reflexão sobre o tema.

O artigo está dividido em quatro seções: a primeira trata das relações entre a etnia e o Estado, e a segunda aborda o debate da etnicidade. A terceira seção analisa a estrutura de desencadeamento do conflito étnico e de que forma ela afeta negativamente os direitos humanos. Em seguida, abordamos a questão da intervenção internacional, como ela se manifesta, qual tem sido sua explicação moral e que relação ela guarda com os interesses dos Estados. Nas considerações finais, concluímos que, de fato, o tema dos direitos humanos, e entre eles a expressão da etnia, ganhou importância e alcançou status de regime internacional sem se dissociar dos temas relativos à política de poder.

\section{ETNIA E ESTADO}

As correntes migratórias dos séculos XIX e XX e o tráfico de escravos dos séculos XVI, XVII e XVIII, entre outros fatores, conformaram um mundo no qual já não existem Estados que não sejam constituídos por uma significativa mistura de povos, etnias e culturas. Em boa parte deles, apesar de eventuais problemas, tem sido possível a convivência pacífica entre os habitantes - e o Brasil pode ser um exemplo disso. Outros países, no entanto, são palco de conflitos étnicos duradouros. Em alguns Estados, a diversidade étnica é incorporada graças a políticas 
públicas especialmente voltadas para ela; em outros, essa mesma diversidade constitui foco de tensão constante. Para explicar tal variação, qualquer argumento simplista tem grande probabilidade de estar equivocado. Afirmar que os conflitos ocorrem apenas em função do ódio determinado pela diversidade ou por disputas de poder significa ignorar a complexidade desses fenômenos. O recurso à etnia como ideologia ou como apelo para a legitimação e coesão de um grupo pode ser usado tanto para fins eleitorais quanto para a guerra. Porém, tratar a etnia apenas como ferramenta para atingir objetivos eleitorais, ou para consolidar uma base social de apoio para a guerra, ou mesmo para buscar recursos de poder, é subestimar o apego que as pessoas efetivamente têm à sua identidade.

De acordo com Horowitz, a gama de questões que envolvem a etnia é enorme:

Em alguns Estados, o conflito étnico desencadeia conflitos com outras clivagens; em outros, ele coexiste com outros tipos de conflitos; em outros ainda, o conflito étnico permanece sob controle. Em alguns Estados, as atitudes interétnicas surgem como inerentemente hostis; em outros passaram por mudanças, benignas ou malignas. Em alguns Estados, conflitos aparentemente sob controle tornaram-se incontroláveis; em outros, o oposto é o verdadeiro. Em alguns Estados, os partidos políticos têm base étnica; em outros, coalizões multiétnicas se formaram (1998:4, tradução dos autores).

Atitudes interétnicas envolvendo clivagens religiosas hostis podem ser exemplificadas por aquelas existentes entre palestinos e israelenses. A antiga Iugoslávia, da Era Tito, constitui uma situação de conflito aparentemente sob controle, mas que, em seguida, pode se tornar incontrolável. Existem Estados em que o contrário ocorreu, como a África do Sul antes e depois do fim do apartheid.

Nos Estados Unidos, os partidos políticos buscam apoio em comunidades étnicas, constituindo, portanto, a princípio, uma coalizão multiétnica. Para consolidar esse apoio, a política internacional é utilizada (Hobsbawm, 2002). Assim, por exemplo, os candidatos fazem promessas nas campanhas eleitorais, e os governantes e legisladores tomam certas medidas internacionais visando angariar os votos dessas coletividades. A comunidade negra preocupa-se com a África; a irlandesa, com a Irlanda e o IRA; os judeus e os muçulmanos, com Israel e o mun- 
do islâmico. Em Estados como Ruanda e Burundi, os partidos políticos que monopolizaram o aparelho estatal tinham base étnica.

Nosso objetivo não será explicar por que as tensões e os conflitos ocorrem em um lugar e não em outro, mesmo porque são inúmeras as variáveis que os motivam. Apesar disso, no entanto, é possível notar uma estrutura-padrão na escalada das crises étnicas que levam aos conflitos violentos. Dessa forma, procuraremos analisar as características dessa estrutura que afetam negativamente os direitos humanos, especialmente conceitos fundamentais para esses direitos, como tolerância, solidariedade, legitimidade, autodeterminação e igualdade. O estudo dessas características pode nos ajudar a pensar casos em que a intervenção internacional, seja ela reivindicada unilateralmente, seja de forma multilateral, busca sua legitimidade em argumentos relacionados aos direitos humanos.

Podemos distinguir dois cenários para pensar como as relações étnicas afetam os direitos humanos. No primeiro, temos uma sociedade multiétnica na qual as relações entre os grupos e os indivíduos ocorrem sem grandes embates; quando ocorrem, o Estado tem capacidade efetiva de processá-los e solucioná-los de maneira compatível com a preservação dos direitos humanos. Isso não significa que não ocorram violações desses direitos, já que é improvável que exista um Estado no qual os direitos humanos não sejam infringidos de algum modo. Mas, nesse cenário, a sociedade como um todo confia no aparelho estatal para dirimir os conflitos e representar seus interesses, sem que seja necessário recorrer à violência e à justiça com as próprias mãos. Podemos recorrer a Duroselle, para quem os "acontecimentos que os governos não controlam deflagram 'forças profundas'"' (2000:187), entendendo essa expressão como uma pulsão. Se a sociedade confia, ao menos em parte, no aparelho estatal, e se este conta com um mínimo de legitimidade para dirimir as desavenças, os conflitos étnicos que eventualmente ocorram não se transformam em grandes embates. Se os governos não controlam ou não querem controlar os acontecimentos e, portanto, são pouco capazes de garantir a preservação dos direitos humanos, então desencadeiam-se forças incontroláveis - as "forças profundas" de que fala Duroselle.

A Figura 1 representa esse primeiro cenário, no qual o governo tem capacidade de impedir o desencadeamento das referidas forças, cumprindo seu papel de proteger os direitos humanos. Nela, triângulos, 
Figura 1

Primeiro Cenário

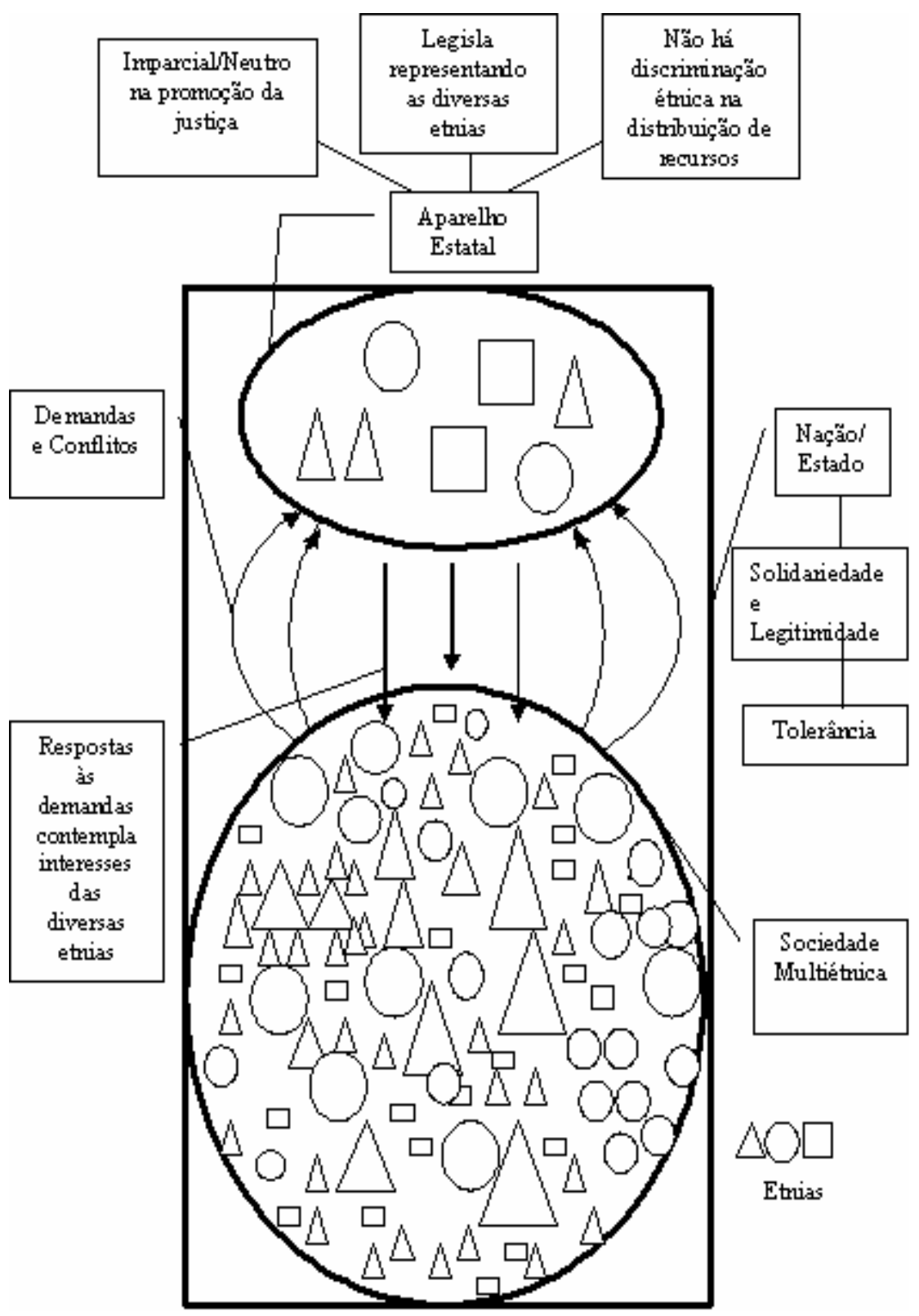


círculos e retângulos representam diferentes etnias que vivem em uma sociedade tolerante. Apesar de haver concentrações étnicas em alguns espaços dessa sociedade, não existem grandes tensões entre os grupos étnicos e todos se vêem como membros de uma mesma nação, isto é, vivem uma relação de solidariedade. Essas concentrações étnicas ocorrem em espaços que podem significar alocações territoriais em bairros ou cidades, especializações em determinadas atividades produtivas, inclusive com distribuição assimétrica de classe, heterogeneidade na distribuição da riqueza etc. A despeito das diferenças existentes, contudo, o governo administra de forma democrática, podendo até mesmo contar com representantes das etnias nas instituições públicas.

O importante para caracterizar uma sociedade como tolerante é a existência de mecanismos capazes de assegurar que nenhum grupo étnico seja marginalizado ou discriminado, garantindo direitos iguais a todos - o que não implica necessariamente proporcionalidade de presença nas instituições públicas. Assim, o aparelho estatal administra demandas e conflitos de forma imparcial e igualitária, promovendo medidas para a inclusão social daqueles que não têm recursos para viver dignamente. Mesmo que algumas pessoas concentrem mais recursos que outras (representadas nas figuras geométricas maiores), não existe a percepção de que os menos abastados sejam privados ou preteridos pelos outros grupos por razões étnicas. Portanto, no plano conceitual, as diferenças de classe não têm conexão com a etnia. Isso não significa que tal conexão não exista no mundo real, mas sim que, em nosso argumento, o Estado não a legitima, em vez disso, procura eliminá-la.

No segundo cenário - elaborado para nos ajudar a pensar como as relações étnicas afetam os direitos humanos e podem servir de base para a busca de legitimidade da intervenção internacional -, o Estado perde ou negligencia sua capacidade de dirimir os conflitos intra-estatais que surgem, ou não está disposto a fazê-lo (ver Figura 2 mais adiante). Em outros termos, ele deixa de responder às demandas da sociedade ou de parte dela de maneira aceitável para todos e de acordo com os preceitos que fundamentam os direitos humanos. Assim, indivíduos e grupos começam a ver uns nos outros uma ameaça à sua existência e aos seus interesses; nesse contexto, a eliminação dessa ameaça passa a ter caráter prioritário. Ou seja, seria uma volta a formas primitivas de vida, formuladas na filosofia política clássica por Hobbes (1983) e identificadas com o estado de natureza. A possibilidade de uma solução negociada é inviabilizada pela falta de confiança no outro e porque 
a disputa, alçada ao nível étnico, atinge a identidade, a dignidade das pessoas; paralelamente, ela se afasta do campo da política ou reduz seu significado. Desse modo, a racionalidade não prevalece, ao menos aquela entendida por Bull (2003) como constituída por um terreno mínimo comum de valores. A título de exemplo, podem-se identificar situações desse tipo nas relações entre partes da direita israelense e partes de grupos fundamentalistas palestinos.

Nesse tipo de cenário, negociar com um grupo étnico adversário pode ser entendido como curvar-se perante o inimigo, o que levaria à perda da dignidade. Dessa maneira, rompem-se os valores e normas essenciais sobre os quais se fundamenta o regime internacional de direitos humanos tal como foi constituído historicamente e vem se consolidando desde a Declaração Universal dos Direitos Humanos, de 1948, até a Declaração de Viena e o Programa de Ação, de 1993 (Alves, 2000). Para alguns, um dos argumentos que explicam a reiteração de situações de ruptura dessas normas, e portanto do regime internacional de direitos humanos, é o fato de que eles se formaram primordialmente sob influência de valores ocidentais, apresentados como universais em razão da assimetria de poder e da hegemonia, não tendo assim absorvido outros sistemas de valores. Em alguns casos, evidencia-se de fato incompatibilidade de valores, e a única forma de contorná-los seria a política, que implica não apenas racionalidade, mas capacidade de aceitar perdas. Um exemplo desses casos pode ser dado por duas etnias que, por razões ancestrais, históricas ou religiosas, disputam o mesmo território, julgando ter a ele direito inalienável e exclusivo. Para entender esse segundo cenário, julgamos necessário conhecer a estrutura de um conflito étnico, como faremos a seguir.

\section{ETNICIDADE}

Existe entre os estudiosos da etnicidade um grande debate a respeito de como defini-la e caracterizá-la. Examinando alguns autores, Szayna (2000) entende que há três grandes perspectivas sobre o tema: a primordialista, a epifenomenalista e a construtivista.

A perspectiva primordialista baseia-se no argumento de que os grupos étnicos são, a priori, "unidades naturais que têm sua coesão derivada de inerentes traços biológicos, culturais ou raciais", que se tornam elementos de diferenciação social especificamente pela dicotomia "nós" e "eles" (ibidem:18). De acordo com essa perspectiva, "os grupos étnicos 
funcionam como universos insulares" (ibidem). O pertencimento a esses grupos é definido pelo acidente do nascimento e, a partir dele, a percepção de que somos distintos uns dos "outros" se consolida ao longo da vida. À medida que os indivíduos aprendem e exercitam sua cultura particular e passam a se relacionar socialmente, seja com os membros de seu próprio grupo, seja com outros grupos, essa distinção vai se afirmando através da comparação das diferenças que existem entre uns e outros.

A perspectiva epifenomenalista, de inclinação marxista, "nega que a etnicidade, como fenômeno social, tenha qualquer base biológica inerente" (ibidem:21). Para os epifenomenalistas, "são as estruturas de classe e os padrões institucionalizados de poder na sociedade que são fundamentais para explicar eventos políticos, em detrimento de qualquer outra formação social baseada na biologia ou na cultura como a 'etnicidade'" (ibidem). Contrariamente à perspectiva primordialista, os epifenomenalistas entendem que as questões étnicas funcionam como uma neblina que encobre as lutas políticas e econômicas. A etnicidade sozinha é, "portanto, meramente uma aparência incidental, não é verdadeiramente causa geradora de nenhum fenômeno social" (ibidem).

A terceira perspectiva, denominada construtivista, deriva do pensamento weberiano e baseia-se no argumento de que a etnicidade é real, mas construída. Os grupos étnicos são

[...] aqueles grupos humanos que desfrutam de uma crença subjetiva de descendência comum por causa de similaridades físicas, culturais ou ambas, ou por causa de memórias da colonização e migração. Essa crença deve ser importante para a propagação da formação do grupo; não importa se efetivamente há ou não um relacionamento de sangue (ibidem:25, tradução dos autores).

Combinada com outros fenômenos sociais, a etnicidade pode ser direcionada à ação social.

De acordo com Horowitz (1998), na prática raramente se trabalha com essas perspectivas de forma rígida, aplicando-se a elas definições mais flexíveis, de acordo com o objeto específico de estudo. Para Szayna (2000:30, tradução dos autores),

o conceito [de etnicidade] vincula três componentes cruciais: características diferenciadoras (qualquer e / ou todas das seguintes: fé, língua, fenótipos, origem ou concentração populacional em uma dada região), 
um sentimento de solidariedade grupal e contato com outro grupo para que se estabeleça a idéia de "outro".

Segundo ele, a etnicidade pode ser definida como o sentimento de afinidade que é compartilhado pelos membros de um grupo. O pertencimento a esse grupo, por sua vez, parte do "mito" da ascendência comum e, ao mesmo tempo, da noção de distinção. O grupo étnico deve ser maior do que o familiar, embora o sentimento de afinidade compartilhada, que deriva do mito da ascendência, possa ser bastante semelhante àquele que caracteriza os laços de família - ainda que a ascendência não seja o único fator capaz de gerar sentimentos coletivos.

Para Moore, o que caracteriza os grupos étnicos são as fronteiras lingüísticas, culturais, raciais e/ou religiosas. Um indivíduo pode ser membro de um grupo étnico "[...] via auto-identificação, por ser tratado como tal por não-membros do seu grupo ou em ambos os casos" (2002:78, tradução dos autores). Na visão de Hobsbawm, a etnicidade está ligada à origem e à descendência comuns, de forma que "[...] a base crucial de um grupo étnico, como forma de organização social, é cultural e não biológica" (2002:78).

As várias definições e caracterizações atribuídas à etnicidade mostram a complexidade dos temas a ela relacionados. Para nossos objetivos, o que importa é captar a realidade das conseqüências políticas que deles decorrem, seja no plano interno dos países, seja pelos efeitos desestabilizadores que acarretam nos âmbitos regionais e mundiais. A falta de consenso em torno das definições do termo não diminui sua importância no debate sobre os grandes problemas vividos pela humanidade ao longo do século XXI. Dessa forma, conhecer a estrutura do conflito étnico pode ser útil na medida em que ajuda a pensar sobre a perda - ou a negligência - da capacidade dos Estados de dirimir os conflitos internos ou sobre sua disposição de promover os direitos humanos. Constatada sua incapacidade, esses Estados poderiam ser definidos como Estados falidos e, nessa condição, possivelmente estaria legitimada a ingerência internacional.

\section{MOBILIZAÇÃO, POLARIZAÇÃO E CONFLITOS ÉTNICOS}

Por que os grupos étnicos se mobilizam? A resposta parece evidente: porque, juntos, os seres humanos têm mais força e legitimidade para atingir seus objetivos. Nos Estados em que as liberdades são garantidas, parece prevalecer a idéia de que a ação dos grupos étnicos é legíti- 
ma, pois visa à busca de seus direitos e de sua identidade. Assim, não se trata de debilitar o Estado, mas de identificar-se com ele. Isso vale para grupos étnicos de origem migrante ou escrava - Estados Unidos e Brasil servem como exemplos. Existindo liberdade, os grupos étnicos cuja origem está relacionada à nacionalidade, ao mesmo tempo em que buscam preservar sua identidade, são fiéis ao Estado no qual estão inseridos - os zulus, na África do Sul, são um exemplo.

Em sociedades nas quais existe tensão étnica e as possibilidades de desenvolvimento são muito limitadas, os grupos étnicos tendem a concentrar recursos em sua própria coletividade, privando assim outros grupos de usufruir deles. Conforme seu nível de gravidade, a concentração de recursos pode desencadear guerras civis ou regionais. Em Estados pobres, ter emprego em um órgão público muitas vezes é a única maneira de alcançar uma vida melhor. Na medida em que os melhores empregos e oportunidades são reservados àqueles que têm melhores níveis de educação, grupos étnicos rivais podem procurar, no limite, monopolizar as instituições e os meios de ensino. Pode ocorrer de o critério utilizado para distribuir vagas e promover o acesso aos meios educacionais ser a etnia. Em outros casos, regras estabelecidas em nome de um ideal nacional comum levam o ensino a ser ministrado apenas na língua do grupo dominante. Situações parecidas podem ocorrer em outros aspectos: integrar ou não a polícia e o Exército; facilitar ou não o acesso a benefícios da reforma agrária, ao crédito, à assistência social, à administração pública etc. Kaldor acredita que, em determinados conflitos étnicos, pode se chegar a uma situação-limite, na qual o grupo dominante considera que "todos os demais devem ser eliminados" (2001:98, tradução dos autores).

A monopolização das instituições e dos recursos com base em critérios étnicos constitui clara violação dos direitos humanos. Trata-se de prática discriminatória na medida em que viabiliza oportunidades desiguais de acesso aos recursos necessários para o desenvolvimento. Colocar limites à expressão das particularidades culturais também é violação e aponta para a falta de unidade e para altos níveis de intolerância da sociedade, que dificilmente pode ser chamada de nação. É disso que deriva a interseção complexa que se dá entre questão étnica e questão nacional. Como analisado por Marshall e Gurr (2003), freqüentemente o fim dos conflitos ocorre com obtenção de maior autonomia do grupo insurgente e, em menor quantidade, pela colocação enfática da 
questão nacional, que em poucos casos levou à secessão ou à constituição de um novo Estado.

Mesmo havendo motivações políticas ou morais para o conflito étnico, a mobilização requer um centro aglutinador: a "política étnica, como toda política, é dirigida pela mobilização (isto é, a habilidade dos líderes de guiar seus seguidores). Não há nada de automático na mobilização étnica" (Moore, 2002:79, tradução dos autores). Kaldor (2001) utiliza o termo "políticas de identidade" para se referir aos movimentos que se processam ao redor de identidades étnicas, raciais ou religiosas com o objetivo de reivindicar o poder estatal:

Uso o termo "identidade" para me referir diretamente a uma forma de rótulo. Se estamos falando de conflitos tribais na África, conflitos religiosos no Oriente Médio ou no Sul da Ásia, ou conflitos nacionalistas na Europa, a característica comum é a maneira pela qual os rótulos são usados como base para reivindicações políticas (ibidem:76, tradução dos autores).

A etnia, tanto quanto outros fatores que podem caracterizar um grupo - classe e nação, por exemplo -, é utilizada para legitimar reivindicações coletivas. Em nossa perspectiva, a etnia, assim como os dois outros conceitos referidos, não pode ser caracterizada como rótulo apenas, como defende a autora. Além de constituir um argumento em torno do qual se mobilizam determinados grupos, a etnia responde a realidades concretas. Em muitos casos, o sentimento de falta de dignidade pode levar uma etnia ou uma nação à mobilização, à insurreição ou à guerra. É o que ocorre com os palestinos.

Isso posto, consideramos factível, a partir da análise crítica do modelo de Szayna (2000), mapear os possíveis caminhos que desencadeiam o confronto étnico. O primeiro passo é observar como os recursos de poder do Estado - políticos, econômicos e sociais - são distribuídos entre os grupos étnicos para, em seguida, verificar se existem movimentações que podem alterar o equilíbrio de poder na sociedade. Tais movimentações são importantes porque poderão abalar o status quo, o que será interpretado como uma ameaça para as diferentes etnias, criando um desequilíbrio que justificaria o conflito. Embora correta, essa afirmação é insuficiente. Ao não levar em conta a intersubjetividade, subestima os fatores culturais e as percepções, isto é, não considera a forma como os grupos podem se perceber em situação de perda de dignidade. 
O segundo passo busca identificar a promoção, pelo Estado ou por grupos não-estatais, de "eventos típicos" que visam à mobilização do grupo. "Eventos típicos são simplesmente quaisquer eventos públicos notáveis que aumentam as sensibilidades dos grupos, reforçam crenças na própria identidade do grupo e desencadeiam espirais de expectativas compartilhadas sobre a resistência coletiva à ordem estabelecida" (ibidem:44, tradução dos autores). Esses eventos confirmam ou justificam medos e ódios, sejam reais, latentes ou imaginários, que poderiam evoluir para tensões e conflitos. Eventos típicos têm diferentes origens - políticas, econômicas e sociais -, mas podem também ter origem em fatos culturais e simbólicos. Em ambas as situações, eles materializam-se através de fatos. As manifestações islâmicas contra os Estados Unidos podem ser analisadas como eventos típicos desencadeadores de ações políticas. Da mesma forma, os atos públicos dos dirigentes sérvios para manter o controle sobre Kosovo também podem ser considerados eventos típicos que levaram ao conflito com os albaneses.

Segundo Szayna (2000), pode haver "empresários de identidade" articulando os eventos típicos. Essas pessoas seriam capazes de catalisar e direcionar para objetivos específicos os sentimentos e os interesses dos grupos nacionais e étnicos - ou seja, as forças profundas de uma coletividade. Para o autor, os objetivos dos empresários de identidade seriam particulares, e esses sentimentos seriam desencadeados de acordo com seus projetos políticos. Nas pesquisas de opinião pública e na análise da literatura, verificamos que, diferentemente do que afirma Szayna, os interesses que levam ao que ele chama de eventos típicos podem também ser resultado da vontade coletiva de grupos nacionais ou étnicos. Nesses casos, a ação que pareceria ser de líderes reflete uma vontade coletiva. Ariel Sharon, em Israel, quando desencadeava ações punitivas e mesmo assassinatos de dirigentes palestinos, refletia a vontade de uma parte de seu povo. Por outro lado, Yasser Arafat, então presidente da Autoridade Palestina, aquiescendo às ações que vitimavam parte da população civil de Israel, também refletia a posição de parte de seu povo.

Ao discutir a situação nos Bálcãs, Alves (2004) ilustra a figura do "empresário de identidade". Ele lembra que "grande parte dos líderes ultranacionalistas balcânicos da década de 1990 eram, como a maioria dos heróis do século XIX, cultivados" (ibidem:61). A idéia de "Grande Sérvia" tem origem no período das grandes lutas nacionalistas da Europa Central e Oriental do século XIX. Boa parte dos líderes eram pes- 
soas cultas, poetas, jornalistas, advogados, médicos e outros profissionais de nível superior.

Na perspectiva de Szayna (2000), a capacidade de liderança e de organização é atributo dessas pessoas e dos grupos que as cercam. Eles direcionam a ação de seus membros para a causa étnica - o que inclui providenciar recursos para as ações. Os métodos empregados para canalizar a ação dos grupos étnicos podem variar bastante: vão desde a utilização do carisma pessoal até a infusão do medo de retaliação que podem sofrer por não agirem de acordo com a causa do grupo. Desse modo, como terceiro passo no mapeamento dos caminhos que levam ao conflito, podemos apontar a existência do empresário de identidade e, como quarto passo, a capacidade que eles têm de canalizar as forças do grupo étnico para objetivos particulares ou coletivos.

Mesmo reconhecendo o papel representado pelo interesse particular dessas pessoas e dos grupos a elas diretamente ligados, não se pode ignorar ou subestimar a origem histórica e material de muitos conflitos, originados em causas que envolvem grandes comunidades. Goldstein e Keohane afirmam que "o impacto de crenças particulares - compartilhadas por um grande número de pessoas - sobre a natureza de seus mundos tem implicações para a ação humana. Tais crenças vão desde princípios morais gerais até acordos sobre um modo específico de aplicar o conhecimento científico" (1993:7, tradução dos autores). Para o nosso argumento, trata-se de sentimentos e valores que não apenas conformam vontades étnicas mas alcançam força concreta e buscam justificativa. Talvez, diferentemente do racionalismo, que produziu importantes correntes de pensamento - o positivismo, a escolha racional, a teoria dos atores racionais, a teoria dos jogos, entre outras -, as questões étnicas tenham explicações que não se conjugam com a compreensão da política tal como o Ocidente a vê. E, quando afirmamos como o Ocidente a vê, queremos dizer que, concretamente, ele também é palco de irracionalismos que escapam ao jogo da política stricto sensu. Assim, podemos compreender os nacionalismos e os conflitos étnicos como parte da política - desde que não dissociada dos sentimentos e da subjetividade.

De acordo com o modelo de Szayna (2000), o quinto e último passo para entender a mobilização étnica é observar a possibilidade de ajuda externa. Em alguns casos, as fronteiras políticas dos Estados, sobretudo na África, não correspondem às disposições geográficas dos grupos 
étnicos. Os "irmãos étnicos" localizados em outros Estados podem fornecer apoio, retórico e/ou material ao grupo em mobilização. Alguns Estados podem achar conveniente apoiar grupos "étnicos subversivos" em outros países, com o intuito de enfraquecê-los, praticando a razão do Estado. Sem dúvida, interesses existem, mas eles podem ter raízes profundas na história. Existem laços familiares, lingüísticos e de costumes entre curdos que vivem em vários Estados ou entre armênios; do mesmo modo, entre judeus vivendo em vários lugares ou entre árabes distribuídos em diversas regiões. Portanto, esses laços podem motivar o apoio, que ocorreria de diversas formas: através da assistência financeira, logística e técnica, e até do apoio diplomático. No Congo, por exemplo, dezenas de milhares de pessoas já foram mortas em conflitos entre grupos étnicos, alguns destes apoiados por Ruanda e Uganda (Amnesty International, 2004).

A discussão do modelo proposto por Szayna (2000) não explica por que alguns grupos utilizam a violência e outros não. Sua relevância está em mostrar que a mobilização étnica é sensível tanto a fatores sentimentais quanto a cálculos racionais. Nossa insistência em apontar também as razões históricas, afetivas, culturais, intersubjetivas e mesmo irracionais, nas forças profundas, deriva do crescente peso que elas vêm tendo nos conflitos regionais e étnicos e nas violações aos direitos humanos.

A mobilização étnica muitas vezes é expressão da luta por direitos humanos; por exemplo, a luta dos negros na África do Sul contra o apartheid. A luta pela preservação dos direitos humanos beneficia-se da liberdade de associação política e do direito de reunião para cultos, ritos e manifestações culturais. Basta lembrar as sociedades nas quais as minorias se organizam para obter força política, sem necessariamente recorrerem a meios violentos generalizados - como é o caso, já comentado, dos negros ou hispânicos nos Estados Unidos. Em outros casos, quando não encontra aberto o caminho institucional, a tolerância e a democracia, a mobilização assume formas reativas, que podem levar à violência generalizada. Em sentido inverso, a violência pode ser utilizada para manter a opressão ou para manter privilégios, dessa forma, impedindo a universalização dos direitos.

Uma vez mobilizados, os grupos étnicos podem alcançar um alto grau de coesão. "Grupos étnicos parecem levar as questões mais além" e parecem manifestar mais lealdade do que outros tipos de grupo, a ponto 
de "se sacrificarem pelo interesse coletivo" (Horowitz, 1998:15, tradução dos autores). Embora suas fronteiras não sejam impermeáveis, imutáveis ou perenes, a mobilização étnica é interessante, uma vez que, nos conflitos, ela possibilita a emergência da dicotomia nós versus eles. Ao se mobilizarem, os grupos tendem a enfatizar características da sua etnia que os distinguem de outros grupos, recorrendo a noções de superioridade e inferioridade, o que pode atingir a dignidade dos outros e enrijecer as fronteiras étnicas - daí a polarização da sociedade entre nós e eles. E essa polarização é fundamental para construirmos o segundo cenário, em que a intolerância, a discriminação e a violência generalizadas rompem com os direitos humanos.

Kaldor (2001:85) observa que os eventos típicos contribuiriam para sensibilizar um dado grupo, de forma que se possa mantê-lo coeso e estimulá-lo à ação. Em situações de conflito, o ódio e as possibilidades de perigo que o outro pode representar são disseminados de diversas formas. O problema é que, "quanto maior o sentimento de insegurança, maior a polarização da sociedade, menor é o espaço para políticas integrativas alternativas" (ibidem:84, tradução dos autores). Ou seja, quanto mais a sociedade se polariza, menores são as possibilidades de se desenvolverem sentimentos como solidariedade e tolerância, fundamentais para garantir a convivência em um Estado capaz de proteger os direitos humanos.

A noção do perigo que o outro pode representar é especialmente importante porque desencadeia dilemas de segurança entre os grupos étnicos. Como confiar no outro? Como saber se o outro se aproxima para efetivamente negociar a paz ou se pretende ganhar tempo para me destruir? Nesse contexto, as pessoas sentem nos membros de outras etnias uma ameaça potencial aos seus interesses e à sua vida. Em grande parte, essa insegurança se deve a atrocidades cometidas - ou supostamente cometidas - em conflitos ocorridos anteriormente e acaba por perpetuar o medo e o ódio na mente dos indivíduos.

O Estado, seja por ineficiência, negligência ou por estar monopolizado por um grupo étnico, deixa de promover relações estáveis e de garantir o respeito às características particulares dos grupos e pessoas que deveria proteger. O caso do Sudão ilustra o que pode significar a noção do perigo que o outro representa. Observemos uma narrativa do conflito que ainda ocorre no Sudão (Human Rights Watch, 2004), palco de rivalidade étnica entre árabes e africanos/negros: 
Tullo Vigevani, Thiago Lima e Marcelo Fernandes de Oliveira

"Os homens a cavalo mataram os meus pais", queixa-se ela [uma garota de 15 anos], referindo-se aos janjaweeds, os bandos de combatentes árabes [...]. Os janjaweeds viajam montados em camelos e cavalos e usam armas automáticas contra aqueles que cruzam o seu caminho [...]. A rivalidade árabe-africana foi fomentada por muito tempo nesta região, e a arma mais implacável tem sido os combatentes janjaweeds a cavalo, que não respeitam nenhum código de guerra. Enquanto os invasores [janjaweeds] saqueiam e incendeiam as casas, os aldeões pegam tudo aquilo que conseguem levar e fogem [...] Fatima Ishag Sulieman, 25, não teve tempo de fugir. Ela estava na cama quando os janjaweeds chegaram. Dois homens entraram na sua cabana. Eles a espancaram e a estupraram em frente à sua família (Lacey, 2004).

É compreensível que a ameaça que os janjaweeds representam para os africanos / negros os impeça de conviver pacificamente com os árabes em uma mesma sociedade, como ocorria até 2001. A disputa sobre as áreas próprias para o cultivo agrícola é um dos motivos dos conflitos (Human Rights Watch, 2004). Contudo, não se pode ignorar as imagens que esses conflitos produzem.

Outro fator que leva à polarização é a tendência ao monopólio étnico dos recursos de poder. Em situações de conflito, cada grupo procurará dispor de mais recursos de poder para viabilizar sua causa, ao mesmo tempo em que tratará de restringir o acesso dos outros a esses mesmos recursos. Cabe ressaltar que não é necessário que o conflito entre etnias seja violento para justificar a busca pela monopolização dos recursos; ela pode ocorrer em Estados em que não existe conflito étnico declarado, sem que a população preterida deseje lutar contra isso. Mas também pode ser o motivo que mobiliza uma coletividade para ação.

Recorrendo a Weber, Szayna (2000) explica que o conflito étnico pode se dar tanto no sentido da exclusão, de cima para baixo - o que pode interessar a quem controla o Estado -, quanto no sentido da usurpação, entendida aqui como a busca de ganhar espaço por aqueles que estão em posição subordinada e que procuram ascender. Segundo ele (ibidem:32, tradução dos autores), "[...] o Estado é que racionaliza os termos legais de closure e dominação, ele se torna a arena central em que os processos de exclusão ou usurpação ocorrem".

Existem casos em que o monopólio étnico do aparelho estatal deixa de ser suficiente para manter um grupo dominante no poder ou se tornou inviável em função de pressões pela democratização. Quando isso 
ocorre - e diante da possibilidade de mudança na distribuição dos recursos internos, isto é, na manutenção dos privilégios e da posição dominante de alguns grupos, que pode configurar um abalo ao equilíbrio de poder -, práticas como o genocídio e a limpeza étnica costumam ser utilizadas para, quando levadas ao extremo, homogeneizar etnicamente a sociedade. Essas práticas dificilmente são concretizadas sem que haja motivações subjetivas que as estimulem. Elas ferem os direitos humanos em vários níveis, uma vez que seus métodos incluem desde a dissuasão de manifestações culturais, com a conseqüente discriminação dos indivíduos, passam pelas restrições colocadas à autodeterminação, até os atentados sistemáticos contra a vida. A tentativa de eliminar a ameaça que o outro representa mostra a fragilidade e mesmo a inadequação das instituições de determinados Estados para fazerem valer os direitos humanos, tais como apresentados na concepção historicamente predominante.

Essas estratégias são utilizadas como terrorismo tanto pelos grupos dominantes, para impor a aceitação do status quo aos grupos opositores, como por estes últimos, para mostrar até onde estão dispostos a ir pela causa étnica ou para provar que aqueles não são invulneráveis. Segundo Saint-Pierre (2003:148), “o fundamento do terror é o sentimento inequívoco de desamparo ante a vontade do terrorista". É verdade que, em um conflito étnico, nem sempre há ruptura total com os direitos humanos, e nem sempre essa ruptura se estende por todo o território do Estado. Porém, com a polarização da sociedade em grupos étnicos rivais e as tentativas de eliminação do outro - como será evidenciado pela Figura 2 -, o Estado não consegue ou não tem interesse em garantir que esses direitos sejam exercidos de maneira pacífica, legítima e institucionalizada.

Dentre as estratégias utilizadas para eliminar os possíveis oponentes ou instaurar o terror, destacam-se (Kaldor, 2001):

1) o assassínio em massa de membros de outras etnias, como ocorreu em Ruanda. Naquele conflito, a elite hutu, que dominava o aparelho estatal, buscava obter a reprodução do próprio poder por meio da coesão que se daria através do apoio do restante da população hutu (mais de $80 \%$ do país). Seu objetivo era justificar a própria permanência no poder, alegando o perigo e a necessidade de se eliminarem os tutsis e os hutus moderados, considerados traidores; 
2) a limpeza étnica, ou seja, a expulsão de um determinado território daqueles grupos pertencentes a diferentes etnias por meio da força ou da coação, como na Bósnia-Herzegovina. Em um dado episódio, os sérvios bósnios, que queriam criar um corredor étnico da Sérvia até Krajina, na Croácia, expulsaram os não-sérvios em Prijedor, na Bósnia. Durante a expulsão, as pessoas "eram forçadas a custear sua própria 'limpeza étnica', pagando taxas de transporte para a 'Cruz Vermelha' local, e eram perturbadas, roubadas e ameaçadas enquanto esperavam os ônibus que as levariam [...]" (Human Rights Watch, 1997);

3) tornar uma dada região inabitável, o que pode ser feito de diversas maneiras: provocar explosões intermitentes e sem distinção de vítimas em locais amplamente povoados; cortar linhas de comunicação e impedir que suprimentos cheguem a determinadas localidades; impedir as pessoas de trabalhar; ultrajar a memória e os costumes locais, destruindo os locais de culto religioso ou marcos históricos; praticar estupro e abuso sexual em lugares públicos. Como exemplos dessas estratégias, poderiam ser mencionados: a ação dos janjaweeds no Sudão, anteriormente referida; as explosões de pessoas-bomba em ônibus em Israel; a dinamitação de casas de palestinos nos territórios ocupados de Gaza e Cisjordânia.

As justificativas para a promoção dessas estratégias que levam à polarização da sociedade encontram respaldo, em maior ou menor grau, tanto na razão quanto na paixão. Kaldor (2001), que prioriza a racionalidade, entende que os conflitos contemporâneos são vinculados a questões étnicas por conveniência. Eles seriam travados sob a bandeira da identidade, mas suas verdadeiras causas estariam ligadas à manutenção ou à conquista do poder. Nesse sentido, empresários de identidade utilizar-se-iam da etnicidade e de algumas de suas características, como a coesão, e principalmente da possibilidade de polarizar a sociedade entre nós e eles, para liderar grupos que sejam capazes de manter sua posição dominante, ou que os ajudem a usurpar o poder. Uma vez polarizada a sociedade, um grupo étnico não alinhado ao grupo dominante passa a ser considerado opositor, secessionista ou subversor potencial - ou seja, ele representa uma ameaça aos interesses e à vida do grupo étnico dominante. Nessas condições, pertencer à etnia dominante pode garantir privilégios e recursos, enquanto pertencer à outra pode representar a marginalização e até o perigo de extinção. 
Por outro lado, há autores que analisam os conflitos étnicos a partir da perspectiva das coletividades; portanto, sem atribuir aos empresários de identidade os rumos que esses conflitos possam tomar. Analisando o processo de paz na questão Israel-Palestina, Hassassian (2001) conclui que a insegurança é um dos principais fatores que levam à polarização entre os israelenses e os palestinos. A evolução histórica do conflito, as sucessivas guerras e os diversos atentados acabaram por impregnar os dois povos de sentimentos de desconfiança e de insegurança, que dificultam o andamento dos processos de paz. É certo que muitos impasses têm como pano de fundo interesses geopolíticos e geoeconômicos, mas o sentimento e a vontade das coletividades são apontados como essenciais para acabar com a polarização e construir a paz.

O fato é que os conflitos étnicos têm como característica a criação de ambientes nos quais as pessoas não possuem um mínimo de segurança e de tranqüilidade. Quanto mais a sociedade se polariza e recorre à violência para atingir seus objetivos políticos, mais a estrutura do Estado se desgasta, conduzindo a um processo de falência do próprio Estado. O conflito étnico provoca a perda do monopólio legítimo da violência. À medida que o governo vai perdendo a confiança de pelo menos uma parte do povo, os grupos passam a se armar e a organizar milícias para se defender, fazer justiça e atingir seus objetivos com suas próprias forças - processo inverso ao da formação do Estado moderno. Alcançado esse estado de desordem, a arrecadação fiscal do governo cai substancialmente, o que inviabiliza suas funções básicas de promoção de justiça, saúde, educação, já que ele se vê obrigado a concentrar recursos em outras áreas. Em seu avanço, a falência do Estado abre espaço para o aumento da privatização da violência, e a função estatal de promover e garantir os direitos humanos deixa de ser praticada.

Privatizada a violência, o Estado perde funções essenciais, inclusive as aprimoradas pela evolução dos direitos humanos, isto é, deixa-se de contar com sua eficiência ou com sua pretensa neutralidade para garantir a liberdade e os direitos fundamentais das pessoas. Quando isso ocorre, há quebra de legitimidade, e o Estado perde a capacidade de resolver as disputas internas. A mediação dos conflitos por meio das instituições deteriora-se e pode extinguir-se. Nos conflitos étnicos, como em outros tipos de conflitos domésticos, "o monopólio legítimo da força foi quebrado. E o que é crucial não é a privatização da violência em si, mas a quebra de legitimidade" (Kaldor, 2001:115, tradução dos auto- 
res). A legitimidade do Estado é fundamental, pois é ela que dá respaldo à convicção de que as pessoas não precisam recorrer à violência.

Quando os grupos étnicos vêem legitimidade no Estado, é no âmbito dele que procuram o diálogo para resolver suas disputas - o que se dá sobretudo nas democracias. Na ocorrência de conflitos étnicos, a negociação que busca sua superação tem como foco a reconstituição da legitimidade do Estado, incorporando membros das etnias em conflito e até observadores internacionais. Em outros casos, quando a polarização da sociedade alcança níveis insuportáveis, a secessão passa a ser a única solução possível.

No plano individual, a polarização e o monopólio étnico dos recursos de poder criam sentimentos de insegurança e a idéia de ilegitimidade. À medida que as tensões vão se agravando - e na expectativa de que elas possam lhes dar segurança -, os indivíduos recorrem a instituições alternativas que, no geral, são gerenciadas por uma das partes em conflito. Isso cria uma espiral que reforça a polarização, reduzindo-se inteiramente o papel mediador do Estado. Os grupos de oposição ao governo procuram alterar o status quo utilizando qualquer meio possível, enquanto os grupos dominantes procuram mantê-lo, recorrendo igualmente a todos os meios possíveis, inclusive ao aparelho estatal.

Nesse estágio, a sociedade claramente torna-se intolerante, e a nação deixa de fazer sentido, pois não há mais razão para a solidariedade. A polarização torna-se mais rígida e mais difícil de ser rompida, visto que o conflito entre os grupos não tem relação apenas com objetivos políticos ou econômicos, mas sobretudo com sentimentos de ódio e de medo de ser exterminado pelo outro. Nesse ponto, a adesão ao grupo étnico confunde-se com a defesa da dignidade individual e coletiva e, dessa forma, qualquer tentativa de negociação passa a ferir a dignidade dos grupos. O simples diálogo com membros de outra etnia pode ser suficiente para alguém ser considerado traidor. A política deixa de existir (Saint-Pierre, 2004).

Esse é o cenário no qual se dá a ruptura com os valores e normas fundamentais dos direitos humanos, de acordo com a concepção institucionalizada pela Organização das Nações Unidas - ONU. Os membros dos grupos étnicos mobilizam-se em torno da etnicidade, polarizando-se. Nesse processo, a sociedade deixa de ser tolerante, e cada grupo ressalta suas particularidades de forma discriminatória. Envolvidos pela lógica de soma zero, na qual o ganho de um significa a perda do 
outro, os grupos buscam concentrar a maior parte dos recursos possíveis, privando os outros do acesso a esses recursos. O mesmo ocorre com o aparelho estatal: os grupos procuram dominá-lo para utilizá-lo conforme seus próprios objetivos - por exemplo, para eliminar o grupo étnico rival. As demandas e os conflitos da sociedade deixam de ter no Estado um árbitro idealmente imparcial, a legislação deixa de ser representativa dos interesses dos diversos grupos étnicos e a igualdade deteriora-se. As pessoas de diferentes etnias não mais se vêem como membros de uma única nação, rompendo os laços de solidariedade e a legitimidade que os unia sob a égide do Estado.

Nesse contexto, representado pelo segundo cenário (Figura 2), os elementos fundamentais sob os quais foi erigida a concepção dominante de direitos humanos são rompidos e, assim, as condições para o exercício e o gozo dos direitos e das liberdades fundamentais - ao menos de acordo com a perspectiva elaborada ao longo de décadas pela ONU encontram-se extremamente deterioradas. Introduzimos, então, a questão das intervenções internacionais para a proteção dos direitos humanos.

\section{A INTERVENÇÃO INTERNACIONAL}

A questão dos direitos humanos ganhou novo fôlego com o final da Guerra Fria, e, conforme já apontado, esperava-se que ela tivesse atingido a universalidade na Conferência da ONU, realizada em Viena, em 1993. Desde então, a expectativa era que a comunidade internacional, não mais constrangida pela estrutura bipolar, fosse mais empenhada em assegurar a proteção internacional dos direitos humanos. Nesse sentido, a Conferência representaria valores incorporados pela comunidade internacional visando criar uma associação de objetivos (Nardin, 1987).

Entende-se por associação de objetivos os valores cooperativos que se fundem em uma concepção de mundo comum e que têm a ver com poder, equilíbrio e riqueza. Nesse caso, a cooperação implica interesses compartilhados. Trata-se, de certa forma, da transposição para as relações internacionais do conceito de nação que, segundo Bauer (1987:160), seria "o conjunto de homens ligados pela comunidade de destino em uma comunidade de caráter". Portanto, a cooperação internacional está ligada à lógica de jogos de soma positiva, e a cooperação 
Figura 2

Segundo Cenário

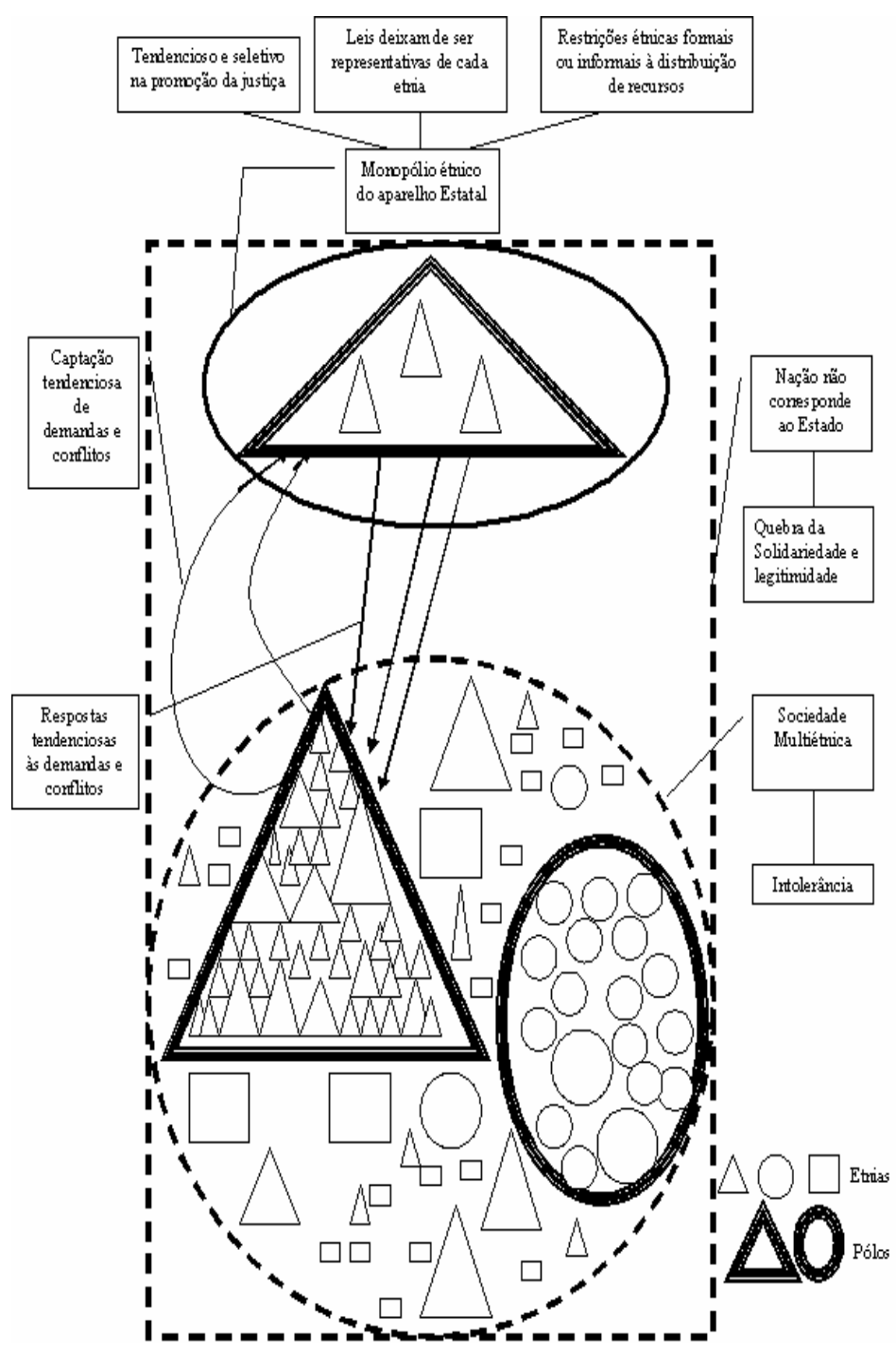

Elaboração dos autores.

no campo dos direitos humanos ocorreria por se ter alcançado um acordo geral em torno de seus conceitos fundamentais.

Os direitos humanos são considerados valores compartilhados para os quais a comunidade internacional estaria disposta a cooperar com o objetivo de protegê-los. A Figura 3 representa como deveria ser a ação 
internacional no caso de uma crise étnica, na qual tais valores possam ser violados. O círculo maior representa a virtual universalidade dos direitos humanos; sua violação em um determinado Estado deveria conduzir a comunidade internacional a agir para restaurá-los. Os hexágonos representam organizações não-governamentais e intergovernamentais que prestam assistência humanitária ao Estado em crise (pontilhado). Algumas delas pressionam esse Estado a promover me-

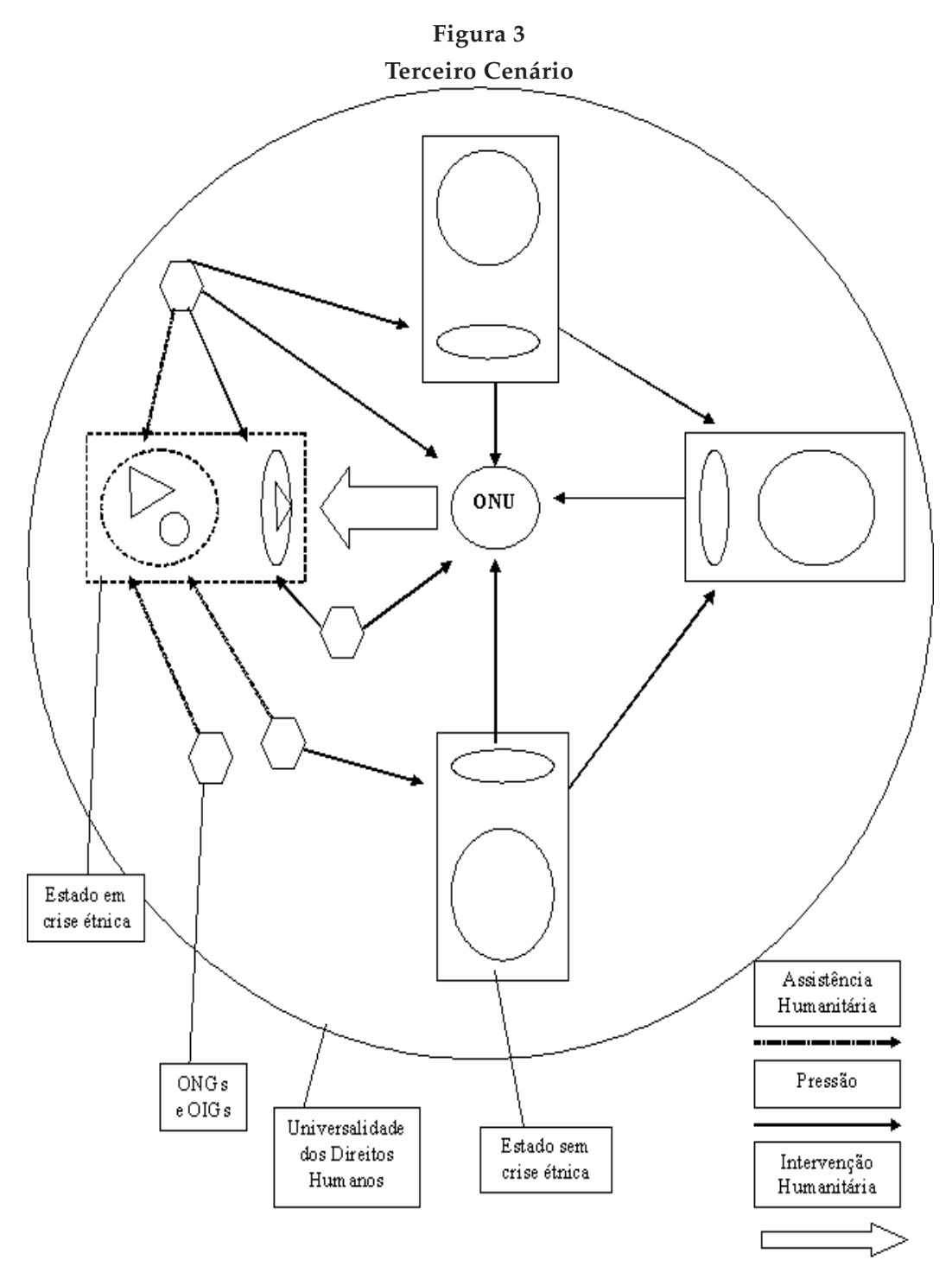

Elaboração dos autores. 
lhores condições para os direitos humanos, elaboram relatórios sobre os acontecimentos e clamam para que outros Estados da comunidade internacional, a ONU e outras organizações internacionais tomem providências. Algumas dessas organizações podem estar aliadas a um determinado grupo étnico. Da mesma forma, também os Estados prestam assistência humanitária e pressionam outros Estados e organizações internacionais a fazê-lo. Na Figura 3, uma vez notificado da situação, o Conselho de Segurança das Nações Unidas, que é composto por Estados, atua no sentido de que sejam construídas ou restabelecidas as condições para o exercício dos direitos humanos.

Em nossa análise, a associação de objetivos não foi alcançada no que diz respeito aos direitos humanos, permanecendo, portanto, como algo apenas normativo. Assim, justificativas de intervenções no caso de violações dos direitos humanos, como aquelas que resultam de conflitos étnicos, teriam outros motivos, diferentes da simples defesa incondicional daqueles direitos. A busca pela solução de conflitos desse tipo é, portanto, seletiva. $\mathrm{O}$ argumento humanitário pode até existir, mas ele se justapõe a outros, de caráter político, econômico e estratégico. Entre os fatores que levam à intervenção, os mais importantes seriam os impactos internacionais, regionais, políticos, econômicos e sociais que as guerras civis ou localizadas acarretam.

Os conflitos ou crises regionais interestatais muitas vezes têm origem nos laços étnicos que atravessam fronteiras - e aqui cabe reiterar que inúmeras fronteiras não correspondem à divisão dos grupos étnicos. Para Moore (2002), podem existir laços étnicos entre a população de dois ou mais Estados quando "os membros do grupo ou são uma maioria dominante ou uma minoria avantajada em um dos dois países. Por exemplo, hindus são uma maioria dominante na Índia e uma minoria no Paquistão. Assim, existe um laço étnico hindu através da fronteira Índia-Paquistão" (ibidem:79, tradução dos autores). Ao tratar das formas de regionalização dos conflitos, ele aponta alguns padrões: laços étnicos aumentam o número de conflitos em termos de política externa, principalmente entre países fronteiriços. Além disso, normalmente os Estados que possuem um grupo étnico dominante ou que se encontram em uma posição privilegiada tendem a ser mais hostis em relação a Estados nos quais seus pares étnicos se encontram em desvantagem ou são discriminados. A tendência a uma maior hostilidade nem sempre se traduz efetivamente em apoio à causa desses pares. Essa prática pode ser melhor visualizada se levarmos em conta que, nos anos 1990, 
44 países apoiaram insurgências em outros Estados, sendo que apenas em dezessete casos os laços étnicos foram apontados como uma das motivações para o apoio. Já em 43 casos, a influência regional foi colocada como parte das motivações. Assim, em dezesseis casos superpõem-se as questões relacionadas a laços étnicos e influência regional. A partir desses dados, Moore observa que, "embora laços étnicos facilitem o apoio internacional, o apoio estatal para insurgências é primeiramente influenciado pela geopolítica" (ibidem:80, tradução dos autores). Dessa forma, a dimensão internacional e regional dos conflitos étnicos deve ser objeto de atenção.

Os laços étnicos exercem influência nos conflitos interestatais e parecem contribuir para a extensão das crises internacionais. Eles tornam o relacionamento diplomático mais conflitivo e podem resultar em apoio a insurgências. Entretanto, é necessário ressaltar que esse apoio ocorre na minoria das vezes. "Os países parecem não desejar invocar medidas punitivas em apoio a grupos vitimados, mesmo na presença de um laço étnico" (ibidem:82, tradução dos autores). Invocar medidas desse tipo para outros Estados poderia servir de estímulo para que o mesmo argumento fosse utilizado contra o próprio Estado. Parece haver uma espécie de acordo tácito quanto a isso.

Outra variável que possibilita a intervenção militar de um Estado em uma guerra civil travada em outro Estado, no qual haja laços étnicos entre partes das populações, é o nível de violência do conflito - ou seja, quanto mais violento o conflito, maior a possibilidade de intervenção estrangeira. Embora seja difícil identificar precisamente em que medida os laços étnicos motivam a intervenção, pode-se dizer que somente um alto nível de vitimação é capaz de desencadear ações humanitárias. Foi o que ocorreu com as intervenções da Economic Community of West African States - ECOWAS na Libéria e Serra Leoa, da Organização do Tratado do Atlântico Norte - OTAN na Bósnia-Herzegovina e Kosovo, e das Nações Unidas no Timor Leste (Moore, 2002). No entanto, apesar do verdadeiro genocídio que caracterizou o conflito étnico entre tutsis e hutus em Ruanda, a comunidade internacional tardou muito a intervir. Do mesmo modo, não houve intervenção na Nigéria e no Sudão, ao menos até agora. Portanto, fica claro que a violência é uma variável importante, mas seu peso é considerado determinante nas intervenções apenas quando associada a interesses de poder e aos impactos internacionais e regionais que pode provocar. 
O conceito de peace making tem por base a idéia de que, não sendo o Estado capaz de garantir os direitos humanos da população ou de parte dela, é preciso que a comunidade internacional o faça - e é aqui que se coloca a questão da intervenção humanitária. De acordo com a concepção de direitos humanos que prevaleceu no debate internacional dos anos 1990, é dever da comunidade internacional intervir para restaurar ou construir condições para a plena vigência dos direitos humanos. No pós-Guerra Fria ganhou ressonância na sociedade internacional o conceito de que "o sofrimento humano em larga escala representa uma ameaça à paz e à segurança internacionais" (Rodrigues, 2000:110). Assim, os direitos humanos passaram a ser vinculados à segurança coletiva. Essa concepção pode ser observada nas resoluções da ONU que autorizaram o uso da força, pois todas relacionaram questões de direitos humanos a ameaças à segurança e à paz internacionais (Rodrigues, 2000). A reiteração dessa lógica marca a consolidação de uma concepção dos direitos humanos na agenda internacional, que se torna, assim, uma espécie de referencial ético ao qual os Estados recorrem para legitimar suas ações. Porém, não sendo a sociedade internacional movida primariamente pela ética dos direitos humanos - e apesar da importância das questões humanitárias nas intervenções internacionais -, não é possível afirmar que ela dá respaldo incondicional, dinâmico e eficiente ao tema. Pelo contrário, a maioria das intervenções tem sido seletiva, pois a comunidade internacional age de modo pendular, ambivalente, oscilando entre a proteção dos direitos humanos e a satisfação dos interesses nacionais, particularmente das grandes potências o que, não necessariamente, são opções excludentes.

\section{CONSIDERAÇÕES FINAIS}

Ao longo do artigo, discutimos conceitualmente como o conflito étnico contrasta com a estrutura ideal de um Estado propício à proteção dos direitos humanos, conforme a concepção predominante na ONU. Iniciamos abordando a questão étnica em relação ao Estado, mostrando a complexidade do tema. Construímos, na primeira seção, o cenário ideal para a proteção desses direitos em um Estado multiétnico. Na segunda seção, abordamos o debate da etnicidade, destacando os elementos de materialidade e de subjetividade ligados às percepções, um passo necessário para discutirmos na terceira seção que sua alta valorização está associada a outros conflitos. Construímos ainda o cenário no qual o conflito étnico torna o Estado impróprio aos direitos humanos. $\mathrm{Na}$ 
quarta, tratamos o tema da intervenção internacional no caso de conflito étnico.

Caminhamos para o encerramento do artigo com uma reflexão sobre as dificuldades da formação de uma associação de objetivos. O reconhecimento da importância dos direitos humanos teria atingido o nível de universalidade com a assinatura de tratados que contam com a adesão de quase todos os Estados que compõem o sistema internacional - a Declaração de Viena e o Programa de Ação, de 1993, foram assinados por todos os membros da ONU. Ainda assim, a ação de muitos Estados não corresponde aos termos acordados. Levando a questão mais além, cabe perguntar: se os tratados e declarações contivessem mecanismos punitivos para os Estados que não os cumprissem, eles teriam recebido todas essas adesões? E ainda: se houvesse mecanismos punitivos, seria possível estabelecer critérios objetivos para sua aplicação? Esse é um dilema importante na atualidade, quando se busca inserir nas regras do comércio internacional, no quadro da Organização Mundial do Comércio-OMC, cláusulas específicas relativas a direitos humanos, sociais e meio ambiente. Havendo sanções, como é o caso da OMC, como aplicá-las, já que as assimetrias de poder podem inviabilizar sua aplicação?

Por outro lado, a experiência da década de 1990 e dos primeiros anos do século XXI coloca uma questão importante: seria a concepção de direitos humanos apontada nos documentos da ONU a melhor para todos os povos? Uma resposta completamente afirmativa não corresponderia ao que os fatos vêm apontando. O que certamente pode ser afirmado é que os conceitos relativos aos direitos humanos não refletem, pelo menos no presente momento, uma associação de objetivos; se refletissem - sobretudo no caso de conflitos étnicos -, eles resultariam em intervenção internacional. $\mathrm{O}$ fato de, em inúmeras ocasiões, isso não acontecer demonstra que o regime internacional é usado seletivamente, sempre conectado a outras considerações. Isso não exclui a possibilidade de que o regime possa induzir a associação de objetivos no futuro. A localização periférica dos conflitos étnicos, apesar de produzir abalos além das fronteiras dos Estados em crise, dificilmente atinge substancialmente os Estados centrais, que são os que detêm maior capacidade para ações. Talvez isso explique a seletividade e o tipo de reações que têm sido observadas. 
Uma dificuldade para a associação de objetivos está na definição de critérios precisos para as intervenções internacionais. Portanto, não defendemos a intervenção automática em situações de violação de direitos, uma vez que a própria caracterização dessas violações está sujeita a elementos de subjetividade, a formas de interpretação, de acordo com o ponto de vista do autor da análise.

Atualmente, parece ganhar espaço a noção de que

[...] a comunidade internacional assumiria a responsabilidade de proteger somente naqueles casos em que os Estados violam deliberadamente esses direitos ou são incapazes de protegê-los [...]. O recurso militar poderia ser empregado quando atendesse a seis critérios: causa justa, intenção correta, último recurso, meios proporcionais, chance razoável de êxito e autoridade adequada (Almino, 2002:76).

Tendo em conta o alto grau de subjetividade desses critérios e, ainda, que eles abrem espaço a outros interesses, cabe questionar aqui a capacidade de se definirem critérios mais rigorosos.

Em suma, o tema dos direitos étnicos e humanos ganhou importância, alcançando status de regime internacional, sem se dissociar dos temas relativos ao poder. Apesar dos avanços de jure, pouco se avançou no sentido de se estabelecer, de facto, uma associação de objetivos nesse campo.

(Recebido para publicação em abril de 2006)

(Versão definitiva em março de 2007) 


\section{REFERÊNCIAS BIBLIOGRÁFICAS}

ALMINO, João. (2002), “Inserção Internacional de Segurança do Brasil: A Perspectiva Diplomática", in Brasil e o Mundo: Novas Visões. Rio de Janeiro, Francisco Alves.

ALVES, José Augusto Lindgren. (2000), "Direitos Humanos, Cidadania e Globalização". Lua Nova, no 50, pp. 185-206.

(2004), “Os Bálcãs Novamente Esquecidos”. Revista Brasileira de Política Internacional, vol. 47, no 1, pp. 55-83.

AMNESTY INTERNATIONAL. (2004), Amnesty International Report. Disponível em http:/ / web.amnesty.org/report2004/2af-index-eng, acessado em 31/5/2004.

BAUER, Otto. (1987), La Question des Nationalités et la Social-Démocratie. Paris, Arcantère Editions, vol. 1.

BULL, Hedley. (2003), A Sociedade Anárquica. Brasília, IPRI.

DUROSELLE, Jean-Baptiste. (2000), Todo Império Perecerá. Brasília/São Paulo, Editora UnB/Imprensa Oficial do Estado.

GOLDSTEIN, Judith e KEOHANE, Robert O. (eds.). (1993), Ideas and Foreign Policy. Beliefs, Institutions and Political Change. Ithaca/London, Cornell University Press.

HASSASSIAN, Manuel. (2001), "Soberania Palestina: Viabilidade e Segurança", in G. Dupas e T. Vigevani (orgs.), Israel e Palestina. A Construção da Paz Vista de uma Perspectiva Global. São Paulo, Editora Unesp, pp. 187-200.

HOBBES, Thomas. (1983), Leviatã. São Paulo, Abril Cultural.

HOBSBAWM, Eric J. (2002), Nações e Nacionalismos desde 1780 (3a ed.). Rio de Janeiro, Paz e Terra.

HOROWITZ, Donald L. (1998), Structure and Strategy in Ethnic Conflict. Disponível em http://www.worldbank.org/html/rad/abcde/horowitz.pdf, acessado em $2 / 2 / 2004$

HUMAN RIGHTS WATCH. (1997), Bosnia and Hercegovina. The Unindicted: Reaping the Rewards of "Ethnic Cleansing". Human Rights Watch Report, vol. 9, o⒈ Disponível em http://www.hrw.org/reports/1997/bosnia/Bosnia.htm\#P75_2298, acessado em 5/5/2004.

(2004), Q \& A: Crisis in Dafur. Disponível em http://hrw.org/english/docs/ 2004/05/05/darfur8536.htm, acessado em 5/5/2004.

KALDOR, Mary. (2001), New and Old Wars. Organized Violence in a Global Era. Stanford, Stanford University Press.

LACEY, Marc. (2004), "Guerra Étnica entre Árabes e Negros Devasta Sudão". The New York Times. Disponível em http://noticias.uol.com.br/midiaglobal/nytimes/ult574u3968.jhtm, acessado em 4/5/2004.

MARSHALL, Monty G. e GURR, Ted Robert. (2003), “Peace and Conflict 2003. A Global Survey of Armed Conflicts, Self-Determination Movements, and Democracy". Center for International Development and Conflict Management, University of Maryland. Disponível em http://www.cidcm.umd.edu/publications/papers/peace_ and_conflict_2003.pdf, acessado em 25/3/2004.

MOORE, Will. (2002), “Ethnic Minorities and Foreign Policy". SAIS Review, vol. 22, no 2, pp. 79-91. 
Tullo Vigevani, Thiago Lima e Marcelo Fernandes de Oliveira

NARDIN, Terry. (1987), Lei, Moralidade e as Relações entre os Estados. Rio de Janeiro, Forense Universitária.

RODRIGUES, Simone Martins. (2000), Segurança Internacional e Direitos Humanos: A Prática da Intervenção Humanitária no Pós-Guerra Fria. Rio de Janeiro, Renovar.

SAINT-PIERRE, Héctor Luis. (2003), “A Necessidade Política e a Conveniência Estratégica de Definir "Terrorismo'". Idéias, ano 10, no 2.

. (2004), A Política Armada. Fundamentos da Guerra Revolucionária. São Paulo, Editora Unesp.

SZAYNA, Thomas S. (ed.). (2000), Identifying Potential Ethnic Conflict. Santa Monica, Rand Corporation. 
Conflito Étnico, Direitos Humanos e Intervenção Internacional

\author{
ABSTRACT \\ Ethnic Conflict, Human Rights, and International Intervention
}

This article discusses how ethnic conflicts negatively affect human rights and how international intervention acts for the defense of these rights. We thus compare the structure by which ethnic conflicts are triggered and an ideal scenario in which the state is capable of guaranteeing human rights, in keeping with the United Nations perspective. While identifying the points at which ethnic conflicts breach the foundations of human rights, we analyze a second scenario in which it is impossible to guarantee such rights, raising the issue of humanitarian intervention. Finally, we argue that although human rights have gained relevance in the post-Cold War period, they do not constitute a cohesive set of objectives. Therefore, in order to understand the selectiveness behind humanitarian interventions, we conclude that it is essential to consider other interests.

Key words: ethnic conflict; human rights; international intervention

\title{
RÉSUMÉ \\ Conflit Ethnique, Droits de l'Homme et Intervention Internationale
}

Dans cet article, on examine comment les conflits ethniques atteignent de façon négative les droits de l'homme et comment a lieu l'intervention internationale en vue de la défense de ces droits. Pour cela, on oppose la structure qui déclenche des conflits ethniques et un cadre idéal où l'État serait capable d'assurer l'exercice des droits humains, selon l'optique soutenue par les Nations Unies. Ainsi, à mesure qu'on dénonce les points où ce genre de conflit mine les fondements de ces droits, on construit un deuxième cadre où ils ne sont pas assurés, et c'est là que se pose la question de l'intervention humanitaire. Enfin, on observe que, malgré l'importance des droits humains dans l'après-Guerre Froide, ils ne forment pas une association d'objectifs. Il faut donc, pour comprendre les critères de sélection qui commandent les interventions humanitaires, prendre en compte d'autres intérêts.

Mots-clé: conflit ethnique; droits humains; intervention internationale 